AperTO - Archivio Istituzionale Open Access dell'Università di Torino

Simultaneous analysis of several synthetic cannabinoids, THC, CBD and CBN, in hair by ultra-high performance liquid chromatography tandem mass spectrometry. Method validation and application to real samples

This is the author's manuscript

Original Citation:

Availability:

This version is available http://hdl.handle.net/2318/99459

since $2015-12-29 T 11: 47: 08 Z$

Published version:

DOI:10.1002/jms.2988

Terms of use:

Open Access

Anyone can freely access the full text of works made available as "Open Access". Works made available under a Creative Commons license can be used according to the terms and conditions of said license. Use of all other works requires consent of the right holder (author or publisher) if not exempted from copyright protection by the applicable law. 


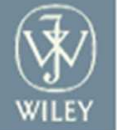

Journal of Mass Spectrometry

\section{Simultaneous analysis of several synthetic cannabinoids, THC, CBD, CBN in hair by ultra-high performance liquid chromatography tandem mass spectrometry. Method validation and application to real samples}

\begin{tabular}{|c|c|}
\hline Journal: & Journal of Mass Spectrometry \\
\hline Manuscript ID: & JMS-12-0003.R1 \\
\hline Wiley - Manuscript type: & Research Article \\
\hline Date Submitted by the Author: & 07-Mar-2012 \\
\hline Complete List of Authors: & $\begin{array}{l}\text { Salomone, Alberto; Centro Regionale Antidoping, Forensic Toxicology } \\
\text { Gerace, Enrico; Centro Regionale Antidoping, Forensic Toxicology } \\
\text { D'Urso, Federica; Centro Regionale Antidoping, Forensic Toxicology } \\
\text { Di Corcia, Daniele; Centro Regionale Antidoping, Forensic Toxicology } \\
\text { Vincenti, Marco; Centro Regionale Antidoping, Forensic Toxicology }\end{array}$ \\
\hline Keywords: & $\begin{array}{l}\text { ultra-high performance liquid chromatography, hair, Spice, synthetic } \\
\text { cannabinoids, method validation }\end{array}$ \\
\hline
\end{tabular}


1 Simultaneous analysis of several synthetic cannabinoids, THC, CBD, CBN in hair by ultra2 high performance liquid chromatography tandem mass spectrometry. Method validation and 3 application to real samples

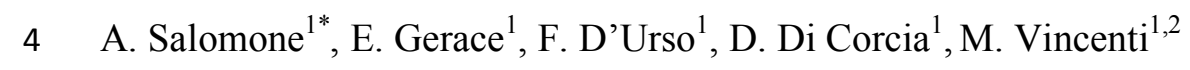

$5 \quad{ }^{1}$ Centro Regionale Antidoping “A. Bertinaria”, Regione Gonzole 10, 10043 Orbassano, Turin, Italy

$6 \quad{ }^{2}$ Dipartimento di Chimica Analitica, Università degli Studi di Torino, via P. Giuria 5, 10125 Turin, Italy

\begin{abstract}
7 Abstract
8 A simple procedure for the quantitative detection of JWH-018, JWH-073, JWH 200, JWH-250, 9 HU-210, $\Delta^{9}$-tetrahydrocannabinol (THC), cannabidiol (CBD) and cannabinol (CBN) in hair has 10 been developed and fully validated. After digestion with $\mathrm{NaOH}$ and liquid-liquid extraction, the 11 separation was performed with an ultra-high performance liquid chromatography system coupled to 12 a triple quadrupole mass spectrometer operating in the selected reaction monitoring mode. The 13 absence of matrix interferents, together with excellent repeatability of both retention times and 14 relative abundances of diagnostic transitions, allowed the correct identification of all analytes 15 tested. The method was linear in two different intervals at low and high concentration, with correlation coefficient values between 0.9933 and 0.9991 . Quantitation limits ranged from 0.07 for JWH-200 up to $18 \mathrm{pg} / \mathrm{mg}$ for CBN. The present method for the determination of several cannabinoids in hair proved to be simple, fast, specific and sensitive. The method was successfully applied to the analysis of 179 real samples collected from proven consumers of Cannabis, among which 14 were found positive to at least one synthetic cannabinoid.
\end{abstract}

\title{
Keywords
}

Hair; ultra-high performance liquid chromatography; synthetic cannabinoids; Spice; method validation

*Corresponding author: Alberto Salomone

Centro Regionale Antidoping “A. Bertinaria”, Regione Gonzole 10/1 - 10043 Orbassano, Torino, Italy
Tel.: +39 011 90224232; FAX.: +39 01190224242 ;
Mobile: +39 3489330145

E-mail: alberto.salomone@antidoping.piemonte .it

32




\section{Introduction}

New synthetic drugs that mimic the psychotropic effects of tetrahydrocannabinol (THC) are proliferating across the world, taking advantage of the delay occurring between their introduction into the market and the legal ban. In the last few years, several herbal mixture declared as incense or air sweeteners became available in "smart shops" in various European countries and were also offered via Internet shops. The substance defined "JWH-018" (naphthalen-1-yl-(1-pentyl-1H-indol3-yl)methanone) was the first cannabimimetic drug identified in 2008, as a psychoactive ingredient in different herbal blends referred to as "Spice" [1,2]. Soon afterwards, several European countries and the Drug Enforcement Administration of the United States undertook legal action to ban this substance together with some of its analogues, progressively synthesized and appearing on the market. Indeed, the efforts to develop new non-steroidal anti-inflammatory agents, possessing high affinity to cannabinoid receptors $\mathrm{CB} 1$ and CB2 led to the synthesis of a series of aminoalkylindoles, whose pharmacological activity was studied [2-5]. Recently, the new cannabimimetic drugs JWH073, JWH-019, JWH-250, JWH-398, JWH-015, JWH-122, JWH-200 and AM-694 have been detected in the black market of different countries [6-9]. Therefore, analytical methods were developed in several forensic laboratories to enable the detection of the new psychoactive substances or their metabolites in either blood or urine [10-16]. A fully validated liquid chromatography-tandem mass spectrometry (LC-MS/MS) method for the detection and quantitation of ten synthetic cannabinoids in human serum revealed high positivity rates $(56.4 \%)$ for at least one aminoalkylindole drug among the 101 serum samples from 80 subjects studied [11]. On the other hand, the occurrence of extensive metabolic processes makes the content of the native drug in urine samples extremely low or totally absent $[13,14]$. Thus, detailed identification of their metabolites, excreted in urine and present also in blood proved to be necessary before any noninvasive screening of the new drugs could be proposed. The cytochrome P450 phase I metabolites of JWH-018 were investigated by in-vitro drug incubation with human liver microsomes, followed by LC-MS/MS analysis [13]. In a later study, the chemical synthesis of five potential JWH-018 invivo metabolites was reported and the quantification of these metabolites in authentic doping control urine samples was assessed [14]. Further studies, identified various metabolites as effective intake markers for a limited number of synthetic cannabinoids, [16-18]. The analysis of real urine samples proved that the illicit consumption of synthetic cannabimimetics can only be ascertained by GC-MS or LC-MS/MS detection of their urinary metabolites and not the original drugs. 
1 Aim of our study was to develop a UHPLC-MS/MS method to detect JWH-018, JWH-073, JWH-

2 200, JWH-250, HU-210, $\Delta^{9}$-tetrahydrocannabinol (THC), cannabidiol (CBD) and cannabinol

$3(\mathrm{CBN})$ in hair samples (Figure 1). The set of investigated substances was coherent with the range of

4 cannabimimetics actually present in the black market during the investigated period of hair

5 sampling. The method was fully validated and applied to the analyses of 179 real samples collected

6 from previously proven Cannabis consumers.

7

8

9

\section{Instrumentation}


1 Analyses were performed on a Shimadzu LC-20A Series system (Shimadzu, Duisburg, Germany)

2 interfaced to an API 5500 triple quadrupole mass spectrometer (Applied Biosystem/Sciex,

3 Darmstadt, Germany) with an electrospray Turbo Ion source operating in the positive ion mode. A

4 Zorbax XDB-C18 column $30 \mathrm{~mm} \times 2.1 \mathrm{~mm}, 1.8 \mu \mathrm{m}$ (Agilent Technologies, Italy), protected by a

$5 \mathrm{C} 18$ guard column, was used for the separation of the target analytes. The column oven was maintained at $50^{\circ} \mathrm{C}$ and the elution solvents were water/formic acid $5 \mathrm{mM}$ (solvent $\mathrm{A}$ ) and acetonitrile (solvent B). After an initial isocratic condition at $75 \%$ A for $0.5 \mathrm{~min}$, the mobile phase composition was varied by a linear gradient (a:b; v/v) from 75:25 to 17:83 in $3.5 \mathrm{~min}$; then isocratic elution at $100 \% \mathrm{~B}$ was established for $1.0 \mathrm{~min}$. The flow rate was $0.8 \mathrm{~mL} / \mathrm{min}$ and the total run time was $7.5 \mathrm{~min}$ including re-equilibration at the initial conditions before each injection. MS/MS detection was executed in the selected reaction monitoring (SRM) mode. In order to establish appropriate SRM conditions, each analyte was individually infused into the electrospray ionization (ESI) capillary and the declustering potential (DP) was adjusted to maximize the intensity of the protonated molecular species $[\mathrm{M}+\mathrm{H}]^{+}$. The collision offset voltage $(\mathrm{CE})$ was set so as to preserve approximately $10 \%$ of precursor ion and the cell exit potentials (CXP) were also optimized. The SRM transitions were monitored during a time window of $\pm 12.5 \mathrm{~s}$ around the expected retention time, and the cycle time of the SRM program was $0.25 \mathrm{~s}$. Optimal signals were obtained using a source block temperature of $500^{\circ} \mathrm{C}$ and an ion-spray voltage of $4000 \mathrm{~V}$. Nitrogen was employed as the collision gas $\left(5 \times 10^{-3} \mathrm{~Pa}\right)$. Both Q1 and Q3 were operated at unit resolution. Gas pressures were set as follows: curtain gas $27.0 \mathrm{psi}$, collision gas $9.0 \mathrm{psi}$, ion source gas (1) $30.0 \mathrm{psi}$ and ion source gas (2) 30.0 psi. SRM transitions and potential settings for the analytes and the internal standard are presented in Table 1.

\section{Method validation}

The method was validated by investigating the following parameters: specificity, linearity, identification and quantitation limits (LOD and LOQ), precision, accuracy [19-21]. Carry-over and matrix effects were also evaluated. Blank hair specimens required for the experiments were obtained from five healthy volunteers (two females, three males).

\section{Selectivity}

The occurrence of possible interferences from endogenous substances was tested on the pool of five blank hair sample by monitoring for each investigated compound the signal-to noise ratio (S/N) of SRM chromatographic profiles at the expected retention time interval. Selectivity was positively ascertained when $\mathrm{S} / \mathrm{N}$ values remained below 3 . 
2 Identification criteria for the analytes were established according to 2006 SOFT/AAFS guidelines

3 [12]. The intra-day and inter-day repeatability of the relative SRM peak intensities for each analyte

4 was determined from five spiked hair samples at a concentration of $50 \mathrm{pg} / \mathrm{mg}$. The inter-day

5 repeatability was verified for three consecutive days.

6

7

8

9

\section{Linearity, limit of detection and limit of quantitation}

Two standard calibration curves at low and high concentrations were prepared by fortifying blank hair samples in the range of, respectively, $1.0-25.0 \mathrm{pg} / \mathrm{mg}(20-500 \mathrm{pg} / \mathrm{mg}$ for THC, CBD, CBN and HU-210) and 20-500 pg/mg (100-1000 pg/mg for THC, CBD, CBN and HU-210). Two replicates for each concentration were analyzed and then averaged to build the curve. The linear calibration parameters were obtained using the least squares regression method. The squared correlation coefficient $\left(\mathrm{R}^{2}\right)$ was used to estimate linearity. Quantitative data resulting from area counts were corrected using the ISTD signal. The limit of detection (LOD) was estimated as the analyte concentration whose response provided a $\mathrm{S} / \mathrm{N}$ value equal to 3 , as determined from the least abundant among the qualifier ions; LOD was extrapolated from $\mathrm{S} / \mathrm{N}$ values of the three lowest concentrations of the calibration curve. The calculated LODs were then experimentally confirmed by analyzing spiked samples at LODs concentration for all analytes. The limit of quantification (LOQ) was estimated based on the $\mathrm{S} / \mathrm{N}$ ratio to be equal or greater than 10 [20].

Matrix effect

The matrix effect was calculated as the mean value obtained from five different hair sources. Hair samples were spiked after the extraction step at the final concentration of $25 \mathrm{pg} / \mathrm{mg}(500 \mathrm{pg} / \mathrm{mg}$ for THC, CBD, CBN and HU-210). For each analyte, the chromatographic peak area were compared with the peak area of standard solutions prepared in methanol, which is the reconstitution solvent. For each sample, analyses were repeated three times. Variability of matrix effect among different hair samples were expressed as $\mathrm{CV} \%$.

\section{Precision and accuracy}

For all analytes, intra-day precision (expressed as percent variation coefficient, CV\%) and accuracy (\%) were evaluated by extracting and analyzing ten replicates of blank hair samples spiked with the standard solutions at two concentration levels (2.5 and $25 \mathrm{pg} / \mathrm{mg}$ for JWH-018, JWH-073, JWH200, JWH-250; 50 and $500 \mathrm{pg} / \mathrm{mg}$ for CBD, CBN, THC, HU-210) covering low and high concentrations of the calibration range. Inter-day precision and accuracy were evaluated by 
1 preparing and analyzing for three consecutive days the same set of ten hair samples used for the 2 intra-day tests. Standard criteria designated satisfactory assay precision when CV\% values were 3 below $25 \%$ for lower concentrations and below 15\% for upper concentrations. Since the acceptance 4 criteria for accuracy are not fixed by internationally standardized rules, we chose that satisfactory 5 accuracy was achieved when the experimentally determined concentrations lied within $\pm 25 \%$ from the expected values. The parameters most commonly changing in everyday toxicological analysis, namely sample volume, reagent batch and operator, were deliberately varied to test if satisfactory accuracy was maintained.

\section{Carry-over}

The background chromatographic profiles for each analyte main transitions were monitored during the analysis of blank hair sample injected for five times after a chromatographic run where a blank hair sample was spiked with all analytes at the highest calibration level. To assure the absence of carry-over, for each transition, the signal to noise ratio $(\mathrm{S} / \mathrm{N})$ had to be lower than 3 .

\section{Results and Discussion}

The optimized UHPLC-MS/MS method allowed the determination of five relevant synthetic cannabinoids plus THC, CBD and CBN in less than 4 min. The whole chromatographic run, comprehensive of the time required for column re-equilibration before the following injection, was completed in $7.5 \mathrm{~min}$. Figure 2 shows a typical UHPLC-MS/MS chromatogram recorded from a hair sample spiked with a mixture of analytes at a concentration of $5 \mathrm{pg} / \mathrm{mg}(100 \mathrm{pg} / \mathrm{mg}$ for THC, CBD, CBN and HU-210).

\section{Method validation}

\section{Identification criteria and selectivity}

For each analyte, the characteristic SRM transitions and retention time are presented in Table 1. The three SRM transitions selected for each analyte provided at least 4 identification points, while the substantial stability of their relative abundances proved compliant for the unambiguous identification of all analytes included in the assay, in agreement with CE/2002/657 decision and 2006 SOFT/AAFS guidelines criteria. The SRM chromatograms of five blank hair samples showed no interfering signals (i.e. S/N value lower than 3) at the retention time interval when each analyte is expected to elute. This demonstrated that the method is selective for all tested compounds and free from positive interference from hair components and column bleeding. 


\section{Linearity, limit of detection and limit of quantitation}

2 The SRM protocol described in Table 1 was used to build the calibration plots for the eight analytes

3 from spiked blank hair samples. A good fit and linearity of the calibration curves was uniformly

4 observed. Range of linearity, $\mathrm{R}^{2}$ values, LOD and LOQ values are showed in Table 2. Positive

5 detection $(\mathrm{S} / \mathrm{N}>3)$ of analytes at the approximate LOD concentrations was confirmed 6 experimentally. LOD values ranged from $0.02 \mathrm{pg} / \mathrm{mg}$ (JWH-200) to $0.18 \mathrm{pg} / \mathrm{mg}$ (JWH-018) for 7 aminoalkylindoles and from $1.2 \mathrm{pg} / \mathrm{mg}$ (THC) to $5.4 \mathrm{pg} / \mathrm{mg}$ (CBD) for cannabinoids. LOQ values

\section{Matrix effect}

The variability among different hair samples was acceptable (CV\% $<25 \%$, as shown in Table 2$)$, so we pooled together the five sources of hair to perform validation experiments such as precision and accuracy. The effect of the real hair matrix appeared to be significant for most of the analytes tested (see Table 2). Large ion suppression is evident for JWH-018 and JWH-250 (matrix effect <-25\%), while ion enhancement is evident for CBD and HU-210 (matrix effect $>+25 \%$ ). In general, ion suppression was observed with the aminoalkylindoles, while ion enhancement occurred with cannabinoids. To compensate as much as possible for the matrix effect present in real hair samples analysis, all calibration and validation tests were conducted on a pool of human hair samples, spiked with the standard analytes solutions. On the other hand, the good linearity observed in the calibration plots demonstrated that the observed matrix effect is proportionally constant, i.e. does not depend on the analytes' concentrations.

\section{Precision and accuracy}

Intra- and inter-day data on precision and accuracy are reported in Table 3. At low concentration, the results showed satisfactory repeatability, as the percent variation coefficient (CV\%) is lower than $15 \%$ for all the spiked analytes; in particular, intra-day precision exhibits $\mathrm{CV} \%$ values ranging from $1.3 \%$ (JWH-200) up to $7.2 \%$ (CBD). At high concentration, the method precision proved also compliant for all analytes, with CV\% values varying from $2.1 \%$ (JWH-200) to $4.8 \%$ (CBN).

Intra-day accuracy expressed as percent bias showed a general trend, with more positive biases observed at low concentrations. However, all the accuracy results were satisfactory, as all biases were below $15 \%$ and widely within the expected $\pm 25 \%$ interval. In particular, at the lower concentration tested, bias values ranged from no-error (JWH-018) to $+14.5 \%(\mathrm{CBN})$, whereas at the higher concentration the bias $\%$ ranged from $-5.2 \%$ (JWH-073) to $+2.8 \%$ (CBD). 
1 At the same concentrations, also the inter-day precision and accuracy proved satisfactory, as the $2 \mathrm{CV} \%$ values ranged from $2.7 \%$ for JWH-250 (at $25 \mathrm{pg} / \mathrm{mg}$ ) to $11.5 \%$ for CBD (at $500 \mathrm{pg} / \mathrm{mg}$ ), 3 while the bias\% ranged from $-6.1 \%$ for JWH-073 and JWH-200 (at $25 \mathrm{pg} / \mathrm{mg}$ ) to +17.4 for CBN (at $4 \quad 50 \mathrm{pg} / \mathrm{mg})$.

5

6

7

8

9

10

11

12

\section{Carry-over}

The background chromatographic profiles for the main transitions of each analyte, which were monitored during the analysis of blank hair extracts injected after highly concentrated samples, did not show the presence of any significant signal (i.e., the $\mathrm{S} / \mathrm{N}$ value was always lower than 3 ) at the retention time intervals of the tested analytes. Therefore, the presence of carry-over effect could be excluded.

\section{Application to real samples}

179 real samples (152 head hair, 27 pubic hair) were collected and analyzed in 2010 in our laboratory arising from subjects that proved to be frequent users of THC-containing products. These hair samples were analyzed once more in 2011 using the present UHPLC-MS/MS method for the potential detection of cannabimimetic drugs. All the samples considered in this study were randomly selected from two groups of subjects, namely driving re-licensing and drug abuse and withdrawal control subjects. Only the proximal 0-6 cm segment was analyzed whenever a longer head hair sample was collected. Shorter head hair, as well as pubic hair samples, were analyzed in their full length. Fourteen (7.82\%) samples were found positive for at least one synthetic cannabinoid, two of which were pubic hair samples (see Table 4). All positive samples originated from male subjects aged $30.0 \pm 9.74$ years (mean $\pm \mathrm{SD} \%$, range 18-48). The average values for THC, CBD and CBN were, respectively, $129.5 \pm 154.2 \mathrm{pg} / \mathrm{mg}$ (range 50-553), 300.3 \pm 552.7 (range 18-1862) and 66.2 \pm 48.0 (range 31-205). The drug most frequently detected was JWH-018, which could be found in 9 samples at concentrations of $28.1 \pm 28.8 \mathrm{pg} / \mathrm{mg} \quad(0.60-70.5 \mathrm{pg} / \mathrm{mg})$, followed by JWH-073 and JWH-250, each found in 8 samples. The concentration of JWH-073 was $116.9 \pm$ $183.2 \mathrm{pg} / \mathrm{mg}(0.50-413.3 \mathrm{pg} / \mathrm{mg})$, whereas the concentration of JWH-250 was $179.6 \pm 242.2 \mathrm{pg} / \mathrm{mg}$ $(1.50-729.4 \mathrm{pg} / \mathrm{mg})$. Although the cut-off level of $50 \mathrm{pg} / \mathrm{mg}$ is internationally accepted for THC in hair, there are no enough data in current literature in order to draft similar conclusion for synthetic cannabinoids. Further studies should be performed in order to discriminate between chronic consumption and occasional use (or external contamination), particularly when the concentration detected are lower than $50 \mathrm{pg} / \mathrm{mg}$. The other analytes included in the method (JWH-200 and HU210) were not identified in any of the analyzed samples. Seven samples were positive for only one 
1 drug, three samples contained two, and four samples contained three synthetic cannabinoids. 2 Totally, 6 samples out of 14 were positive for at least one synthetic cannabinoid at level higher than

3

$50 \mathrm{pg} / \mathrm{mg}$. The chromatogram of a real sample positive to THC, CBD, CBN, JWH-018, JWH-073 and JWH-250 is shown in Figure 3. The samples that were positive for JWH-018 and JWH-073 were collected between February and December 2010, although the Italian Ministry of Health had included these two cannabinoids into the list of prohibited substances since June 2010. The first sample positive to JWH-250 was collected in June 2010 (length: $3.5 \mathrm{~cm}$, result: $209 \mathrm{pg} / \mathrm{mg}$ ), although this drug was banned in Italy only since May 2011. JWH-200 and HU-210 have not been specifically banned yet, but, in any case, all the hair samples tested in the present study proved negative to their presence. Apparently, these two substances were not yet present in the Italian black market during the year 2010 .

\section{Conclusions}

The present UHPLC-MS/MS method proved suitable for the detection and quantitation of several synthetic cannabinoids in keratinic matrix, taking advantage from the fact that the original drugs, not their metabolites, are found in hair samples. The proposed method allows a fast determination of all target compounds in a single run of 4.0 minutes plus 3.5 min of column re-equilibration time. In general, the introduction of UHPLC-MS/MS drastically reduced the analysis time required for carrying out the toxicological procedures, hence achieving a drastic increase of the overall laboratory productivity without sacrificing chromatographic resolution, accuracy and precision. Nonetheless, the method appears to be sufficiently flexible to include new substances and more Internal Standards, for a continuously expanding set of analytes.

The present method was successfully applied to the analysis of 179 real samples from frequent Cannabis consumers with the aim of understanding the recent diffusion of cannabimimetics in the overall drug abuse. Plausibly, consumers of cannabimimetics have to be found chiefly among former or still active Cannabis consumers, whose incidence in the general population is, in turn, quite accurately estimated. To our knowledge, this is the first inference study on cannabimimetics consume in the Italian territory, which has to be repeated with a larger panel of analytes and clear reference to both a fixed period of time and a comparative population of casually sorted subjects. Despite the statistical limitations of the present approach, it was nevertheless demonstrated a noteworthy presence of positive samples in the investigated target population, showing that the consume of synthetic cannabinoids is being a health emergency, at least among Cannabis abusers since early 2010. Further in-depth examinations are needed to investigate this phenomenon, possibly including the new substances that are progressively introduced into the black market and 
1 exploring other populations of potential consumers. Nonetheless, tentative cut-off levels should be 2 proposed in order to discriminate between chronic consumption and occasional use (or external 3 contamination), or to elucidate if the cut-off of $50 \mathrm{pg} / \mathrm{mg}$ used for THC in hair might be similarly 4 accepted for synthetic cannabinoids.

5

6 Acknowledgments

7 We gratefully thank the Department for Anti-drug Policies of the Presidency of the Council of 8 Ministers and the National Institute of Health (Rome, Italy) for providing the reference standards.

9 The generous financial contribution from the Compagnia di San Paolo (Turin, Italy) for acquiring 10 the analytical instrumentation utilized in the present work is gratefully acknowledged (Grant 11 411/PV-2009.1993). We are also indebted to the Regione Piemonte for its continuous financial 12 support of our toxicology laboratory. 
References

V. Auwärter, S. Dresen, W. Weinmann, M. Müller, M. Pütz, N. Ferreirós. 'Spice' and other herbal blends: harmless incense or cannabinoid designer drugs? J. Mass Spectrom. 2009, 44, 832.

B.K. Atwood, J. Huffman, A. Straiker, K. Mackie. JWH018, a common constituent of 'Spice' herbal blends, is a potent and efficacious cannabinoid $\mathrm{CB}_{1}$ receptor agonist. $\mathrm{Br} . J$. Pharmacol. 2010, 160, 585.

[3] J.W. Huffman. Cannabimimetic indoles, pyrroles and indenes. Curr. Med. Chem. 1999, 6,705 .

[4] M.M. Aung, G.Griffin, J.W. Huffman, M. Wu, C. Keel, B. Yang, V.M. Showalter, M.E. Abood, B.R. Martin. Influence of the N-1 alkyl chain length of cannabimimetic indoles upon $\mathrm{CB}(1)$ and $\mathrm{CB}(2)$ receptor binding. Drug and Alcohol Dependence 2000, 60, 133.

[5] J.W. Huffman, Cannabimimetic indoles, pyrroles, and indenes: structure-activity relationships and receptor interactions, in: P.H. Reggio (Ed.), The Cannabinoid Receptors, Humana Press, Totowa, NJ, 2009, pp. 49-94.

[6] S. Dresen, N. Ferreirós, M. Pütz, F. Westphal, R. Zimmermann, V. Auwärter. Monitoring of herbal mixtures potentially containing synthetic cannabinoids as psychoactive compounds. J. Mass Spectrom. 2010, 45, 1186.

[7] S. Hudson, J. Ramsey, L. King, S. Timbers, S. Maynard, P.I. Dargan, D.M. Wood. Use of high-resolution accurate mass spectrometry to detect reported and previously unreported cannabinomimetics in "herbal high" products. J. Anal. Toxicol. 2010, 34, 252.

[8] N. Uchiyama, M. Kawamura, R. Kikura-Hanajiri, Y. Goda. Identification and quantitation of two cannabimimetic phenylacetylindoles JWH-251 and JWH-250, and four cannabimimetic naphthoylindoles JWH-081, JWH-015, JWH-200, and JWH-073 as designer drugs in illegal products. Forensic Toxicol. 2011, 29, 25.

[9] H.J. Penn, L.J. Langman, D. Unold, J. Shields, J.H. Nichols. Detection of synthetic cannabinoids in herbal incense products. Clin. Biochem. 2011, 44, 1163.

[10] A. Grigoryev, S. Savchuk, A. Melnik, N. Moskaleva, J. Dzhurko, M. Ershov, A. Nosyrev, A. Vedenin, B. Izotov, I. Zabirova, V. Rozhanets. Chromatography-mass spectrometry studies on the metabolism of synthetic cannabinoids JWH-018 and JWH-073, psychoactive components of smoking mixtures. J. Chromatogr. B 2011, 879, 1126.

[11] S. Dresen, S. Kneisel, W. Weinmann, R. Zimmermann, V. Auwärter, Development and validation of a liquid chromatography-tandem mass spectrometry method for the 
quantitation of synthetic cannabinoids of the aminoalkylindole type and methanandamide in serum and its application to forensic samples. J. Mass Spectrom. 2011, 46, 163.

[12] J. Teske, J.P. Weller, A. Fieguth, T. Rothämel, Y. Schulz, H.D. Tröger. Sensitive and rapid quantification of the cannabinoid receptor agonist naphthalen-1-yl-(1-pentylindol-3-yl) methanone (JWH-018) in human serum by liquid chromatography-tandem mass spectrometry. J. Chromatogr. B 2010, 878, 2959.

[13] A. Wintermeyer, I. Möller, M. Thevis, M. Jübner, J. Beike, M.A. Rothschild, K. Bender. In vitro phase I metabolism of the synthetic cannabimimetic JWH-018. Anal. Bional. Chem. 2010, 398, 2141.

[14] S. Beuck, I. Möller, A. Thomas, A. Klose, N. Schlörer, W. Schänzer, M. Thevis. Structure characterisation of urinary metabolites of the cannabimimetic JWH-018 using chemically synthesised reference material for the support of LC-MS/MS-based drug testing. Anal. Bional. Chem. 2011, 401, 493.

[15] T. Kraemer, K.Y. Rust, M. Meyer, D. Wissenbach, D. Bregel, M. Hopf, H. Maurer, J. Wilske. Studies on the metabolism of JWH-018 and of a homologue of CP 47,497, pharmacologically active ingredients of different misused incense (“spice”) using GC-MS and LCMSn techniques. Ann. Toxicol. Anal. 2009, 21.

[16] T. Sobolevsky, I. Prasolov, G. Rodchenkov. Detection of JWH-018 metabolites in smoking mixture post-administration urine. Forensic Sci. Int. 2010, 200, 141.

[17] A. Grigoryev, A. Melnik, S. Savchuk, A. Simonov, V. Rozhanets. Gas and liquid chromatography-mass spectrometry studies on the metabolism of the synthetic phenylacetylindole cannabimimetic JWH-250, the psychoactive component of smoking mixtures. J. Chromatogr. B 2011, 879, 2519.

[18] C.L. Moran, V.H. Le, K.C. Chimalakonda, A.L. Smedley, F.D. Lackey, S.N. Owen, P.D. Kennedy, G.W. Endres, F.L. Ciske, J.B. Kramer, A.M. Kornilov, L.D. Bratton, P.J. Dobrowolski, W.D. Wessinger, W.E. Fantegrossi, P.L. Prather, L.P. James, A. Radominska-Pandya, J.H. Moran. Quantitative measurement of JWH-018 and JWH-073 metabolites excreted in human urine. Anal. Chem. 2011, 83, 4228.

[19] SOFT, AAFS Forensic toxicology laboratory guidelines. SOFT and AAFS. 2006.

[20] F.T. Peters, O.H. Drummer, F. Musshoff, Validation of new methods. Forensic Sci. Int. 2007, 165, 216.

[21] F. Musshoff, B. Madea. New trends in hair analysis and scientific demands on validation and technical notes. Forensic Sci. Int. 2007, 165, 204. 
1 Table 1. SRM transitions and corresponding potentials for the target compounds and internal standard.

\begin{tabular}{|c|c|c|c|c|c|c|}
\hline \multirow{4}{*}{$\begin{array}{l}\text { Compound } \\
\text { JWH-200 }\end{array}$} & \multirow{4}{*}{$\begin{array}{c}\begin{array}{c}\text { RT } \\
(\mathbf{m i n})\end{array} \\
1.03\end{array}$} & \multicolumn{2}{|c|}{$\begin{array}{c}\text { SRM transitions }{ }^{\mathrm{a}} \\
(\mathrm{m} / \mathrm{z})\end{array}$} & \multirow{2}{*}{$\begin{array}{l}\text { DP } \\
(\mathbf{V}) \\
53\end{array}$} & \multirow{2}{*}{$\begin{array}{c}\text { CE } \\
(\mathbf{V}) \\
29\end{array}$} & \multirow{2}{*}{$\begin{array}{c}\text { CXP } \\
(\mathbf{V}) \\
20\end{array}$} \\
\hline & & 385.2 & $\rightarrow \quad 155.1$ & & & \\
\hline & & 385.2 & $\rightarrow \quad 114.0$ & 53 & 32 & 18 \\
\hline & & 385.2 & $\rightarrow \quad 127.0$ & 53 & 62 & 20 \\
\hline \multirow{3}{*}{ JWH-250 } & \multirow{3}{*}{3.17} & 336.2 & $\rightarrow \quad 121.0$ & 68 & 29 & 19 \\
\hline & & 336.2 & $\rightarrow \quad 91.0$ & 68 & 62 & 15 \\
\hline & & 336.2 & $\rightarrow \quad 200.3$ & 68 & 34 & 15 \\
\hline \multirow{3}{*}{ JWH-073 } & \multirow{3}{*}{3.22} & 328.1 & $\rightarrow \quad 155.0$ & 85 & 32 & 15 \\
\hline & & 328.1 & $\rightarrow \quad 200.2$ & 85 & 31 & 17 \\
\hline & & 328.1 & $\rightarrow \quad 127.0$ & 85 & 62 & 21 \\
\hline \multirow{3}{*}{ CBD } & \multirow{3}{*}{3.39} & 315.0 & $\rightarrow \quad 193.2$ & 40 & 30 & 10 \\
\hline & & 315.0 & $\rightarrow \quad 123.0$ & 40 & 43 & 19 \\
\hline & & 315.0 & $\rightarrow \quad 259.2$ & 40 & 27 & 11 \\
\hline \multirow{3}{*}{ JWH-018 } & \multirow{3}{*}{3.47} & 342.1 & $\rightarrow \quad 155.1$ & 41 & 31 & 13 \\
\hline & & 342.1 & $\rightarrow \quad 214.2$ & 41 & 32 & 9 \\
\hline & & 342.1 & $\rightarrow \quad 127.1$ & 41 & 55 & 13 \\
\hline \multirow{3}{*}{$\mathrm{CBN}$} & \multirow{3}{*}{3.67} & 311.1 & $\rightarrow \quad 223.2$ & 64 & 28 & 17 \\
\hline & & 311.1 & $\rightarrow \quad 195.1$ & 64 & 36 & 8 \\
\hline & & 311.1 & $\rightarrow \quad 241.3$ & 64 & 27 & 8 \\
\hline \multirow{3}{*}{ HU-210 } & \multirow{3}{*}{3.67} & 387.3 & $\rightarrow \quad 243.1$ & 110 & 25 & 10 \\
\hline & & 387.3 & $\rightarrow \quad 71.1$ & 110 & 27 & 10 \\
\hline & & 387.3 & $\rightarrow \quad 261.1$ & 110 & 24 & 11 \\
\hline \multirow{3}{*}{ THC } & \multirow{3}{*}{3.85} & 315.0 & $\rightarrow \quad 193.0$ & 45 & 30 & 8 \\
\hline & & 315.0 & $\rightarrow \quad 123.1$ & 45 & 44 & 12 \\
\hline & & 315.0 & $\rightarrow \quad 259.1$ & 45 & 27 & 10 \\
\hline \multirow[b]{2}{*}{ JWH-018- $d 9$} & \multirow[b]{2}{*}{3.46} & 351.2 & $\rightarrow \quad 154.9$ & 70 & 35 & 21 \\
\hline & & 351.2 & $\rightarrow \quad 127.3$ & 70 & 62 & 11 \\
\hline
\end{tabular}

${ }^{\mathrm{a}}$ Target transitions used for quantitation are marked in bold

4 Table 2. Range of calibration, linearity, LODs and LOQs values, and matrix effect for all analytes

\begin{tabular}{|c|c|c|c|c|c|c|c|c|}
\hline \multirow[b]{2}{*}{ Compound } & \multicolumn{2}{|c|}{ Low levels } & \multicolumn{2}{|c|}{ High levels } & \multirow[b]{2}{*}{$\begin{array}{c}\text { LOD } \\
(\mathrm{pg} / \mathrm{mg})\end{array}$} & \multirow[b]{2}{*}{$\begin{array}{c}\mathrm{LOQ}^{\mathrm{a}} \\
(\mathrm{pg} / \mathrm{mg})\end{array}$} & \multicolumn{2}{|c|}{ Matrix effect $^{b}$} \\
\hline & $\begin{array}{c}\text { Linearity } \\
\text { Range } \\
\text { (pg/mg) }\end{array}$ & $\begin{array}{c}\text { Correlation } \\
\text { coefficient } \\
\left(\mathbf{R}^{2}\right)\end{array}$ & $\begin{array}{c}\text { Linearity } \\
\text { Range } \\
\text { (pg/mg) }\end{array}$ & $\begin{array}{c}\text { Correlation } \\
\text { coefficient } \\
\left(\mathbf{R}^{2}\right)\end{array}$ & & & $\begin{array}{l}\text { Mean } \\
( \pm \%)\end{array}$ & CV\% \\
\hline JWH-200 & $1-25$ & 0.9941 & $20-200$ & 0.9959 & 0.02 & 0.07 & -7.6 & 19.5 \\
\hline JWH-250 & $1-25$ & 0.9974 & $20-200$ & 0.9997 & 0.04 & 0.13 & -30.9 & 20.0 \\
\hline JWH-073 & $1-25$ & 0.9991 & $20-200$ & 0.9963 & 0.10 & 0.33 & -19.9 & 19.7 \\
\hline CBD & $20-500$ & 0.9985 & $100-800$ & 0.9957 & 5.4 & 18 & +32.1 & 19.8 \\
\hline JWH-018 & $1-25$ & 0.9985 & $20-500$ & 0.9968 & 0.18 & 0.59 & -59.1 & 10.3 \\
\hline $\mathrm{CBN}$ & $20-500$ & 0.9968 & $100-1000$ & 0.9958 & 1.6 & 5.3 & +11.8 & 12.6 \\
\hline HU-210 & $20-200$ & 0.9933 & $100-1000$ & 0.9943 & 3.0 & 9.9 & +29.8 & 11.9 \\
\hline THC & $20-500$ & 0.9980 & $100-1000$ & 0.9954 & 1.2 & 3.9 & +8.9 & 21.9 \\
\hline
\end{tabular}


1

2 Table 3. Intra/Inter-day precision (CV\%) and accuracy (bias\%) for each analyte tested.

\begin{tabular}{|c|c|c|c|c|c|}
\hline \multirow[b]{2}{*}{ Compound } & \multirow[b]{2}{*}{$\begin{array}{c}\text { Concentration } \\
\text { (pg/mg) }\end{array}$} & \multicolumn{2}{|c|}{ Intraday $(n=10)$} & \multicolumn{2}{|c|}{ Interday $(n=30)$} \\
\hline & & $\begin{array}{c}\text { Precision } \\
\text { (CV\%) }\end{array}$ & $\begin{array}{c}\text { Accuracy } \\
(\text { Bias\%) }\end{array}$ & $\begin{array}{c}\text { Precision } \\
(\mathrm{CV} \%)\end{array}$ & $\begin{array}{c}\text { Accuracy } \\
\text { (Bias\%) }\end{array}$ \\
\hline \multirow{2}{*}{ JWH-200 } & 2.5 & 1.3 & \multirow[t]{2}{*}{+6.1} & 4.4 & \multirow[t]{2}{*}{+4.6} \\
\hline & 25 & 2.1 & & 6.8 & \\
\hline \multirow{2}{*}{ JWH-250 } & 2.5 & 2.3 & \multirow{2}{*}{${ }_{-4.5}+2.0$} & 7.2 & -4.8 \\
\hline & 25 & 2.4 & & 2.7 & -5.0 \\
\hline \multirow{2}{*}{ JWH-073 } & 2.5 & 1.9 & \multirow{2}{*}{$\begin{array}{rr} & +8.6 \\
-5.2 & \end{array}$} & 8.2 & -1.4 \\
\hline & 25 & 3.4 & & 4.4 & -6.1 \\
\hline \multirow{2}{*}{ CBD } & 50 & 7.2 & +5.7 & 9.9 & \multirow[t]{2}{*}{+1.4} \\
\hline & 500 & 2.8 & +2.8 & 11.5 & \\
\hline \multirow{2}{*}{ JWH-018 } & 2.5 & 4.2 & 0.0 & 5.8 & \multirow{2}{*}{$\begin{array}{l}-4.3 \\
\end{array}$} \\
\hline & 25 & 2.3 & -3.0 & 4.2 & \\
\hline \multirow{2}{*}{ CBN } & 50 & 2.0 & +14.5 & 8.8 & +17.4 \\
\hline & 500 & 4.8 & +0.4 & 11.0 & +1.5 \\
\hline \multirow{2}{*}{ HU-210 } & 50 & 3.1 & +13.6 & 7.9 & +13.8 \\
\hline & 500 & 2.3 & +2.6 & 5.8 & +0.9 \\
\hline \multirow{2}{*}{ THC } & 50 & 1.7 & +13.4 & 6.4 & \multirow[b]{2}{*}{-1.9} \\
\hline & 500 & 2.2 & -1.7 & 8.4 & \\
\hline
\end{tabular}

3

4

5

6

7

8

9

10

11

12

13

14

15

16

17

18

http://mc.manuscriptcentral.com/jms 
1 Table 4. Synoptic summary of real samples positive to synthetic cannabinoids

\begin{tabular}{cccccccccc}
\hline $\begin{array}{c}\text { Positive } \\
\text { case }\end{array}$ & Age & Gender & $\begin{array}{c}\text { Type of } \\
\text { hair }\end{array}$ & $\begin{array}{c}\text { THC } \\
(\mathbf{p g} / \mathbf{m g})\end{array}$ & $\begin{array}{c}\text { CBD } \\
(\mathbf{p g} / \mathbf{m g})\end{array}$ & $\begin{array}{c}\text { CBN } \\
(\mathbf{p g} / \mathbf{m g})\end{array}$ & $\begin{array}{c}\text { JWH-018 } \\
\mathbf{( p g} / \mathbf{m g})\end{array}$ & $\begin{array}{c}\text { JWH-073 } \\
(\mathbf{p g} / \mathbf{m g})\end{array}$ & $\begin{array}{c}\text { JWH-250 } \\
(\mathbf{p g} / \mathbf{m g})\end{array}$ \\
\hline 1 & 29 & male & head & 73 & 42 & 64 & 70.5 & 413.3 & - \\
2 & 29 & male & pubic & 68 & 57 & 67 & 1.5 & - & - \\
3 & 18 & male & head & 553 & 1217 & 137 & 38.3 & - & - \\
4 & $\mathrm{n} / \mathrm{a}$ & male & head & 70 & 55 & 36 & - & 1.3 & 208.8 \\
5 & 22 & male & head & 57 & $<$ LOQ & 39 & 70.4 & 37.0 & 729.4 \\
6 & 22 & male & head & 57 & 222 & 60 & - & - & 1.5 \\
7 & 48 & male & head & 54 & 25 & 31 & 44.9 & 409.3 & 262.0 \\
8 & 43 & male & head & 50 & 24 & 36 & 0.8 & 0.5 & - \\
9 & 20 & male & head & 69 & 85 & 62 & - & - & 67.4 \\
10 & 26 & male & pubic & 60 & 88 & 60 & - & 1.7 & - \\
11 & 32 & male & head & 115 & 460 & 51 & 10.9 & 66.7 & 138.6 \\
12 & 44 & male & head & 59 & 38 & 31 & 0.6 & - & - \\
13 & 37 & male & head & 417 & 1862 & 205 & 14.8 & 5.2 & 2.9 \\
14 & 20 & male & head & 112 & 18 & 47 & - & - & 26.0 \\
\hline
\end{tabular}

3

4

5

6

7

8

\section{FIGURE CAPTIONS}

Figure 1

Figure 2

Figure 3

Molecular structures of the screened compounds

MRM chromatogram of a blank hair sample fortified with the target compounds at final concentration of 5 pg/mg for JWH-200, JWH-250, JWH-073, JWH-018 and 100 pg/mg for CBD, CBN, HU-210 and THC.

Analysis of a real sample positive to THC, CBD, CBN, JWH-018, JWH-073 and JWH-250. 


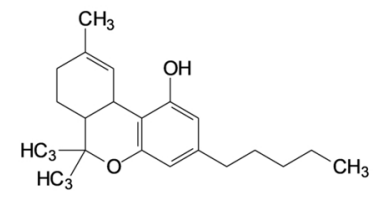

THC

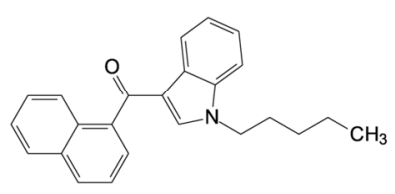

JWH-018

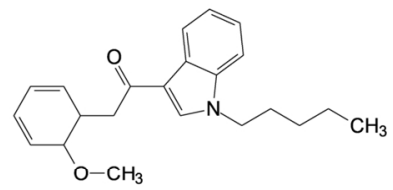

JWH-250
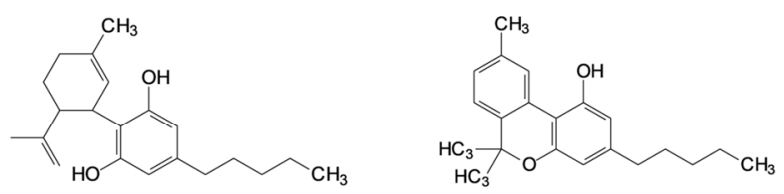

CBD

CBN

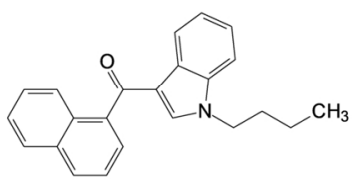

JWH-073

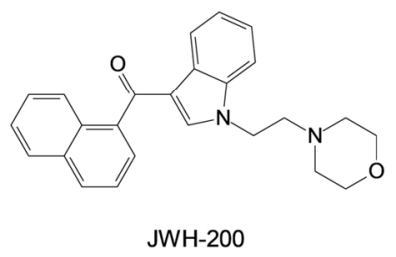

но

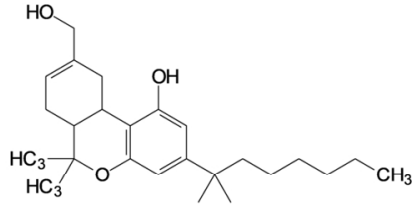

\section{$75 \times 50 \mathrm{~mm}(600 \times 600 \mathrm{DPI})$}




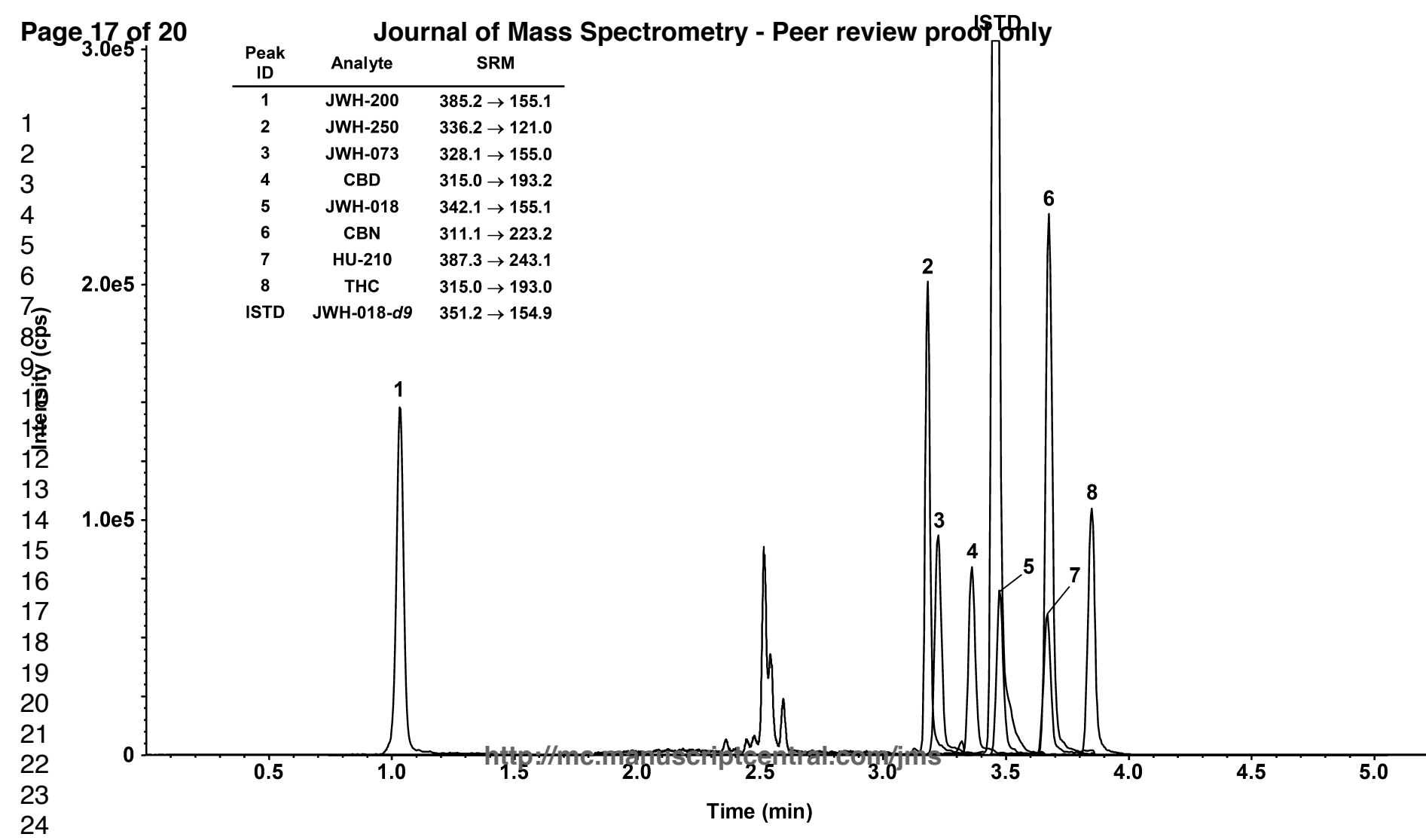




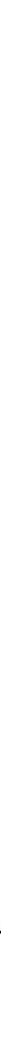

